\title{
Delayed gastrointestinal recovery after abdominal operation - role of alvimopan
}

This article was published in the following Dove Press journal:

Clinical and Experimental Gastroenterology

5 August 2015

Number of times this article has been viewed

\author{
Nicholas G Berger \\ Timothy J Ridolfi \\ Kirk A Ludwig \\ Division of Colorectal Surgery, \\ Department of Surgery, Medical \\ College of Wisconsin, Milwaukee, \\ Wisconsin USA
}

Correspondence: Kirk A Ludwig Division of Colorectal Surgery, Department of Surgery, Medical College of Wisconsin, 9200 W. Wisconsin Ave, Milwaukee,Wisconsin 53226, USA Email kludwig@mcw.edu

\begin{abstract}
Postoperative Ileus (POI), which occurs after surgical manipulation of the bowel during abdominal operations, is associated with prolonged hospital stay, increasing medical costs, and delayed advancement of enteral diet, which contributes to a significant economic burden on the healthcare system. The use of accelerated care pathways has shown to positively impact gut function, but inevitable postoperative opioid use contributes to POI. Alvimopan is a peripherally acting $\mu$-opioid receptor antagonist designed to mitigate antimotility effects of opioids. In our review, we examined ten trials on alvimopan's use after abdominal operations. Several of the earlier studies on patients undergoing bowel resection showed correlations between the study group and GI recovery as defined by passage of flatus, first bowel movement, and time to readiness for discharge. Data in patients undergoing total abdominal hysterectomy showed similarly decreased GI recovery time. Additionally, data within the past few years shows alvimopan is associated with more rapid GI recovery time in patients undergoing radical cystectomy. Based on our review, use of alvimopan remains a safe and potentially cost-effective means of reducing POI in patients following open GI surgery, radical cystectomy, and total abdominal hysterectomy, and should be employed following these abdominal operations.
\end{abstract}

Keywords: postoperative ileus, alvimopan, ileus, bowel resection, return of bowel function

\section{Introduction}

Postoperative ileus (POI) is a transient impairment of normal gastrointestinal (GI) motility seen after major abdominal operations and periodically after nonabdominal operations, with characteristics including nausea and vomiting, bloating, abdominal pain and discomfort, absence of passage of flatus or stool, accumulation of gas and fluid in the bowel, and poor tolerance of oral intake. ${ }^{1}$ Surgical manipulation of the intestine during surgery correlates with decreased contraction of intestinal smooth muscle,$^{2}$ and the use of postoperative opioids for pain control acts on enteric nervous system $\mu$-receptors, slowing intestinal transit times. ${ }^{3}$ Therefore, after major abdominal surgery, POI is often a foregone conclusion, prolonging hospital stay, increasing medical costs, and delaying advancement of enteral diet. Recent data indicate a significant economic burden on the health care system in the care of POI, approaching US $\$ 1.5$ billion annually. ${ }^{4}$

With such profound impact on economics and patient comfort, POI remains an important issue for health care, specifically relating to abdominal surgery. To this end, several measures are aimed at reducing the duration and magnitude of POI. These measures each address the various factors that impact on postoperative gut function, and all are variably included in accelerated-care pathways. The major elements of 
these care pathways include the nonuse of nasogastric tubes in the postoperative period, opioid-sparing analgesia, early mobilization, intravenous fluid restriction, early feeding, and the use of prokinetics and other drugs that have been shown to have a positive impact on postoperative gut function. ${ }^{5}$ However, sparing opioids after surgery remains a difficult task, as many patients still require opioid pain control following major abdominal surgery. As such, specific treatments to lessen the negative impact of these narcotics on postoperative bowel dysfunction are thought to be valuable. Alvimopan is an oral, peripherally acting $\mu$-opioid receptor antagonist designed to mitigate antimotility effects of opioids on the GI tract without compromising opioid-based analgesia. ${ }^{6}$ In this review, the role of alvimopan in GI recovery of bowel resection after abdominal operation, and as a corollary, hospital costs, safety, and side effects are considered.

\section{Materials and methods}

In our systematic review of the literature, a US National Institutes of Health's National Library of Medicine PubMed online literature search was employed. Key search terms included "alvimopan", "post-operative ileus", "ileus", "return of bowel function", and "bowel resection". Inclusion criteria included published data from randomized controlled trials and meta-analyses specifically studying alvimopan as an experimental variable in POI after open operations, including bowel resection. Exclusion criteria included studies on patients who did not undergo abdominal operations. Ten publications were found that met our search and inclusion criteria.

\section{Results}

\section{Postoperative ileus}

Several controlled trials have examined administration of alvimopan in the postoperative period and its effects on GI recovery after open abdominal surgery. In 2001, the first of these trials was reported in the New England Journal of Medicine which studied 78 patients, most of whom underwent total abdominal hysterectomy. Time to passage of flatus and bowel movement was decreased, along with an associated decrease in the time to readiness for discharge in the alvimopan group. ${ }^{7}$ This study paved the way for several multicenter randomized double-blind trials showing correlation with alvimopan and GI recovery, as well as time to hospital discharge after abdominal surgery ${ }^{8,9}$ and decreased requirement of nasogastric tube placement. ${ }^{10}$

In patients undergoing total abdominal hysterectomy and treated with alvimopan postoperatively for 7 days (in hospi- tal and at home), alvimopan significantly decreased time to first bowel movement and flatus, as well as demonstrating subjectively better bowel movement quality in the alvimopantreatment arm. Adverse events up to 30 days after surgery were also monitored, with the most common of these being nausea, vomiting, constipation, and gas pain, with no statistical significance of adverse events between the placebo and alvimopan groups. ${ }^{11}$ When administered to patients undergoing open bowel resection, alvimopan significantly accelerated GI recovery and hospital discharge compared to an accelerated postoperative care pathway alone. ${ }^{12}$ Furthermore, in a pooled analysis of four Phase III randomized double-blind controlled trials examining adult patients undergoing laparotomy with partial small or large bowel resections, alvimopan was shown to improve time to tolerance of oral diet and passage of first stool, as well as time to discharge order written. Moreover, number-needed-totreat analysis demonstrated that treating seven patients would decrease length of hospital stay by 1 day. ${ }^{13}$

Since the publication of these randomized controlled trials, several meta-analyses have been performed with the aggregated data. In 2007, Tan et al published a meta-analysis of trials in patients undergoing bowel resection or total abdominal hysterectomy in which GI recovery was measured. The results of this meta-analysis of 2,195 patients showed that alvimopan improved time to tolerance of solid food, passage of flatus and stool (GI-3), and time to tolerance of solid food and passage of stool (GI-2). As with prior studies, no significant difference was noted in treatment-emergent adverse events, including nausea, vomiting, abdominal distention, constipation, and gas pain. ${ }^{14}$ A second meta-analysis of patients undergoing abdominal surgery who were treated with accelerated-care pathways pooled 1,388 patients, in which half received alvimopan. Analysis revealed that treatment with alvimopan in the perioperative period resulted in reduction in time to hospital discharge order, GI-3, and GI-2 recovery. One limitation of this meta-analysis was the absence of data in the use of alvimopan following laparoscopic surgery. ${ }^{15}$

More recently, a multicenter randomized double-blind placebo-controlled trial of alvimopan in 277 patients following radical cystectomy was published by the European Association of Urology. All patients undergoing radical cystectomy were eligible if they received postoperative intravenous opioid-based patient-controlled analgesia and removal of nasogastric tube by the morning of postoperative day 1 , and a standardized postoperative care pathway was used that included ambulation protocol, diet advancement on postoperative day 3, exclusion of epidural anesthesia/ analgesia, and opioid-sparing medication (ketorolac or 
COX-2 inhibitors) dose restriction. This study showed statistically significant more rapid GI-2 recovery with a shorter mean length of stay and less ileus-related morbidity in the alvimopan arm. ${ }^{16}$

\section{Safety, side effects, and FDA approval}

Data gained from randomized trials on POI have shown overall that alvimopan has similar treatment-emergent adverseevent profiles compared to placebo with regard to nausea, vomiting, gas pain, and abdominal distension. In a 2007 analysis of four prospective alvimopan POI trials, POI-related morbidity was examined. In alvimopan-treatment groups, overall postoperative morbidity, nasogastric tube insertion, and overall complications of POI were less than placebo. ${ }^{17}$ One safety concern with alvimopan relates to adverse cardiac events in patients with opioid-induced bowel dysfunction being treated with low-dose $0.5 \mathrm{mg}$ twice-daily alvimopan over 12 months. A single trial demonstrated a nonsignificant trend toward more cardiac-related adverse events. ${ }^{18}$

As a result of the POI trials and demonstration of safety, the US Food and Drug Administration (FDA), approved alvimopan in 2008 for the treatment of POI, with ongoing evaluation to ensure continued benefit. Via the Entereg Access Support and Education Program, hospital pharmacies must be registered and pharmacists and practitioners trained in the administration of alvimopan. Additionally, it was approved for inpatient use only, allowing for $12 \mathrm{mg}$ preoperative dosing plus $12 \mathrm{mg}$ twice-daily administration for 7 days from the operative day, for the indication of POI. ${ }^{19}$

\section{Cost analysis}

POI following abdominal surgery increases patient morbidity and length of stay, resulting in health care economic burden. Alvimopan is approved for POI, but data on its cost-effectiveness have not been examined in Phase III randomized trials. Using data gained from a Phase IV trial of alvimopan for POI following radical cystectomy, the cost versus benefit of alvimopan was examined. Medication use, procedures, total hospital days, and readmissions related to POI were recorded for the 277 patients in the original study. The authors demonstrated that POI-related health care costs were lower for alvimopan by $\$ 2,340$ per patient, significant compared to placebo, and mean total combined costs were diminished by $\$ 2,640$ per patient. ${ }^{20}$

In two retrospective matched-cohort studies of patients undergoing bowel resection, outcomes of total hospital costs and cost components and length of stay were compared between the control and study arms. The first of these studies, published in 2011, matched 480 alvimopan patients with two controls each. Mean total hospital costs were shown to be statistically significant at $\$ 1,040$ less per patient, and length of stay for the alvimopan patients was significantly different compared to controls. Upon subanalysis of laparoscopic versus open procedures, costs did not differ significantly. ${ }^{21}$ The second of these studies, published in 2014, examined data from the University Health System Consortium and matched patients undergoing bowel resection receiving alvimopan with appropriate controls. Laparoscopic and open cohorts were analyzed, with the laparoscopic alvimopan cohort exhibiting shorter length of stay and intensive care unit (ICU)-admission rate, and the open cohort showed shorter length of stay and ICU-admission rate as well as lower overall hospital cost when both groups were compared to controls. Furthermore, outcomes in the alvimopan cohort, including length of stay, ICU-admission rate, and hospital costs, were all significantly lower. ${ }^{22}$

\section{Discussion}

Since alvimopan gained FDA approval for inpatient use in 2008 , its safety has been adequately demonstrated in clinical trials, with no observable difference in treatment-related adverse-event profiles compared to placebo. It should be noted that safety concerns related to adverse cardiac events were observed in patients being treated for opioid-induced bowel dysfunction, not POI, and they were administered alvimopan in a vastly different dosing strategy than currently recommended. Also, the incidence of adverse cardiac events was not significantly different when compared to controls.

In the aforementioned cost-benefit analyses, alvimopan was shown to reduce postoperative health care costs for patients undergoing radical cystectomy and bowel-resection operations, which if implemented following a wider range of abdominal operations, could greatly reduce total health care dollars spent during the postoperative period.

Acute-phase reactants in the systemic inflammatory response following abdominal surgery are mitigated with laparoscopic versus open procedures. ${ }^{23}$ This raises questions regarding the efficacy of POI-reducing drugs like alvimopan in laparoscopy. A paucity of data exists in the use of alvimopan in the setting of laparoscopic surgery; therefore, the argument for its use in this setting is not as strong. While recent retrospective data show promise for alvimopan following laparoscopic bowel resection for reducing POI, data on length of hospital stay and hospital costs are conflicting. ${ }^{22,24,25}$ 
POI remains a major factor in determining length of hospital stay, patient morbidity, and medical costs after abdominal operation. Accelerated-care pathways and early advancement of diet offer low-cost options of reducing length of stay and health care dollars spent. ${ }^{26}$ However, these advancements are still hindered by the widespread and necessary use of opioids for postoperative pain control following abdominal surgery, making ileus-mitigating alvimopan an appropriate option for reducing POI following abdominal surgery. Continued data showing improvement in length of hospital stay and reduction of POI with direct correlation with ileus-related costs and overall postoperative costs will have a large impact on the implementation of alvimopan into postoperative acceleratedcare pathways for abdominal surgery.

\section{Conclusion}

The several aforementioned clinical trials, pooled analyses, and meta-analyses provide a strong argument in favor of the use of alvimopan following open GI surgery, radical cystectomy, and total abdominal hysterectomy. The current dosing strategy follows FDA recommendations and most study parameters, with one $12 \mathrm{mg}$ preoperative dose given up to 2 hours prior to surgery and twice-daily $12 \mathrm{mg}$ dosing while an inpatient postoperatively. This regimen for the indication of POI has been shown to improve GI-2 recovery and decrease length of hospital stay in the treatment arms of these trials.

\section{Disclosure}

The authors report no conflicts of interest in this work.

\section{References}

1. Vather R, Trivedi S, Bissett I. Defining postoperative ileus: results of a systematic review and global survey. J Gastrointest Surg. 2013;17(5): 962-972.

2. Kalff JC, Schraut WH, Simmons RL, Bauer AJ. Surgical manipulation of the gut elicits an intestinal muscularis inflammatory response resulting in postsurgical ileus. Ann Surg. 1998;228(5):652-663.

3. Bohn LM, Raehal KM. Opioid receptor signaling: relevance for gastrointestinal therapy. Curr Opin Pharmacol. 2006;6(6):559-563.

4. Goldstein JL, Matuszewski KA, Delaney CP, et al. Inpatient economic burden of postoperative ileus associated with abdominal surgery in the United States. P T. 2007;32(2):82-90.

5. Basse L, Thorbøl JE, Løssl K, Kehlet H. Colonic surgery with accelerated rehabilitation or conventional care. Dis Colon Rectum. 2004;47(3): 271-277; discussion 277-278.

6. Becker G, Blum HE. Novel opioid antagonists for opioid-induced bowel dysfunction and postoperative ileus. Lancet. 2009;373(9670):1198-1206.

7. Taguchi A, Sharma N, Saleem RM, et al. Selective postoperative inhibition of gastrointestinal opioid receptors. $N$ Engl J Med. 2001;345(13): 935-940.

8. Delaney CP, Weese JL, Hyman NH, et al. Phase III trial of alvimopan, a novel, peripherally acting, mu opioid antagonist, for postoperative ileus after major abdominal surgery. Dis Colon Rectum. 2005;48(6): 1114-1125; discussion 1125-1126; author reply 1127-1129.
9. Viscusi ER, Goldstein S, Witkowski T, et al. Alvimopan, a peripherally acting mu-opioid receptor antagonist, compared with placebo in postoperative ileus after major abdominal surgery: results of a randomized, double-blind, controlled study. Surg Endosc. 2006; 20(1):64-70.

10. Wolff BG, Michelassi F, Gerkin TM, et al. Alvimopan, a novel, peripherally acting mu opioid antagonist: results of a multicenter, randomized, double-blind, placebo-controlled, phase III trial of major abdominal surgery and postoperative ileus. Ann Surg. 2004;240(4):728-734; discussion 734-735.

11. Herzog TJ, Coleman RL, Guerrieri JP Jr, et al. A double-blind, randomized, placebo-controlled phase III study of the safety of alvimopan in patients who undergo simple total abdominal hysterectomy. Am J Obstet Gynecol. 2006;195(2):445-453.

12. Ludwig K, Enker WE, Delaney CP, et al. Gastrointestinal tract recovery in patients undergoing bowel resection: results of a randomized trial of alvimopan and placebo with a standardized accelerated postoperative care pathway. Arch Surg. 2008;143(11):1098-1105.

13. Ludwig K, Viscusi ER, Wolff BG, Delaney CP, Senagore A, Techner L. Alvimopan for the management of postoperative ileus after bowel resection: characterization of clinical benefit by pooled responder analysis. World J Surg. 2010;34(9):2185-2190.

14. Tan EK, Cornish J, Darzi AW, Tekkis PP. Meta-analysis: alvimopan vs placebo in the treatment of post-operative ileus. Aliment Pharmacol Ther. 2007;25(1):47-57.

15. Vaughan-Shaw PG, Fecher IC, Harris S, Knight JS. A meta-analysis of the effectiveness of the opioid receptor antagonist alvimopan in reducing hospital length of stay and time to GI recovery in patients enrolled in a standardized accelerated recovery program after abdominal surgery. Dis Colon Rectum. 2012;55(5):611-620.

16. Lee CT, Chang SS, Kamat AM, et al. Alvimopan accelerates gastrointestinal recovery after radical cystectomy: a multicenter randomized placebo-controlled trial. Eur Urol. 2014;66(2):265-272.

17. Wolff BG, Weese JL, Ludwig KA, et al. Postoperative ileus-related morbidity profile in patients treated with alvimopan after bowel resection. J Am Coll Surg. 2007;204(4):609-616.

18. Mortensen E. Entereg ${ }^{\circledR}$ (alvimopan) OBD study GSK014 safety findings. 2008. Available from: http://www.fda.gov/ohrms/dockets/ ac/08/slides/2008-4336s1-04-Adolor-Mortensen.pdf. Accessed June 2, 2015.

19. Cubist Pharmaceuticals I. Entereg (alvimopan) risk evaluation and mitigation strategy (REMS). 2013. Available from: http://www.accessdata. fda.gov/drugsatfda_docs/label/2013/021775s0101bl.pdf. Accessed June 2, 2015.

20. Kauf TL, Svatek RS, Amiel G, et al. Alvimopan, a peripherally acting $\mu$-opioid receptor antagonist, is associated with reduced costs after radical cystectomy: economic analysis of a phase 4 randomized, controlled trial. J Urol. 2014;191(6):1721-1727.

21. Poston S, Broder MS, Gibbons MM, et al. Impact of alvimopan (Entereg) on hospital costs after bowel resection: results from a large inpatient database. P T. 2011;36(4):209-220.

22. Simorov A, Thompson J, Oleynikov D. Alvimopan reduces length of stay and costs in patients undergoing segmental colonic resections: results from multicenter national administrative database. Am J Surg. 2014;208(6):919-925; discussion 925.

23. Delgado S, Lacy AM, Filella X, et al. Acute phase response in laparoscopic and open colectomy in colon cancer: randomized study. Dis Colon Rectum. 2001;44(5):638-646.

24. Obokhare ID, Champagne B, Stein SL, Krpata D, Delaney CP. The effect of alvimopan on recovery after laparoscopic segmental colectomy. Dis Colon Rectum. 2011;54(6):743-746.

25. Kelley SR, Wolff BG, Lovely JK, Larson DW. Fast-track pathway for minimally invasive colorectal surgery with and without alvimopan (Entereg): which is more cost-effective? Am Surg. 2013;79(6):630-633.

26. Lau C, Phillips E, Bresee C, Fleshner P. Early use of low residue diet is superior to clear liquid diet after elective colorectal surgery: a randomized controlled trial. Ann Surg. 2014;260(4):641-647; discussion 647-649. 
Clinical and Experimental Gastroenterology

Dovepress

\section{Publish your work in this journal}

Clinical and Experimental Gastroenterology is an international, peerreviewed, open access journal, publishing all aspects of gastroenterology in the clinic and laboratory, including: Pathology, pathophysiology of gastrointestinal disease; Investigation and treatment of gastointestinal disease; Pharmacology of drugs used in the alimentary tract;

Immunology/genetics/genomics related to gastrointestinal disease. This journal is indexed on CAS. The manuscript management system is completely online and includes a very quick and fair peer-review system. Visit http://www.dovepress.com/testimonials.php to read real quotes from published authors.

Submit your manuscript here: http://www.dovepress.com/clinical-and-experimental-gastroenterology-journal 